\title{
Natural killer cells: from basic research to treatments
}

\author{
Eric Vivier ${ }^{1,2,3,4 *}$ and Sophie Ugolini ${ }^{1,2,3 *}$ \\ Centre d'Immunologie de Marseille-Luminy, Université de la Méditerranée UM 631, Marseille, France \\ 2 INSERM, UMR-S 631, Marseille, France \\ ${ }^{3}$ CNRS, UMR 6102, Marseille, France \\ ${ }^{4}$ Assistance Publique des Hôpitaux de Marseille, Hôpital de la Conception, Marseille, France \\ *Correspondence: vivier@ciml.univ-mrs.fr; ugolini@ciml.univ-mrs.fr
}

\section{INNATE IMMUNITY AND NK CELLS}

The immune system is classically divided into innate and adaptive. Adaptive immunity can be defined by the presence of cells (i.e., $\mathrm{T}$ and $\mathrm{B}$ lymphocytes in higher vertebrates) that clonally express a colossal repertoire of receptors (i.e., the $\mathrm{T}$ cell and the $\mathrm{B}$ cell antigen receptors), the diversity of which results from somatic DNA rearrangements. Besides $\mathrm{T}$ and $\mathrm{B}$ cells, natural killer (NK) cells have been originally defined as cytolytic lymphocytes that selectively eliminate tumor cells without antigen-specific receptors (Oldham and Herberman, 1973; Herberman et al., 1975; Kiessling et al., 1975). NK cells are lymphocytes of the innate immune system that can kill an array of target cells and secrete cytokines that participate to the shaping of the adaptive immune response (Vivier et al., 2008, 2011). A feature of NK cells resides in their capacity to distinguish stressed cells (such as tumor cells, microbe-infected cells, cells which have undergone physical or chemical injuries) from normal cells via an array of germline-encoded recognition receptors.

The acquisition of cell cytotoxicity during evolution has been associated with the development of highly sophisticated and robust mechanisms that control the initiation of the cytolytic processes and avoid tissue damage. Along this line, much progress has been made over the last 15 years in the dissection of the mechanisms that allow NK cells to discriminate target cells from other healthy "self" cells. These data have been instrumental in defining several immune recognition strategies and in the emergence of the "dynamic equilibrium concept." The NK cell detection system includes a variety of cell surface activating and inhibitory receptors, the engagement of which regulates NK cell activities. Thus, the integration of antagonistic pathways upon interaction with neighboring cells governs the dynamic equilibrium regulating NK cell activation and dictates whether or not NK cells are activated to kill target cells (Moretta and Moretta, 2004; Vivier et al., 2004; Lanier, 2005).

\section{MISSING-SELF AND NK CELL EDUCATION}

Natural killer cells use inhibitory receptors to gauge the absence of constitutively expressed self-molecules on susceptible target cells. In particular, NK cells express MHC class I-specific receptors and "lose" inhibitory signals when encountering MHC class I-deficient hematopoietic cells in several in vitro and in vivo models. As a consequence, NK cells can recognize "missing self" on hematopoietic cells (Kärre et al., 1986; Bix et al., 1991). The MHC class I-specific inhibitory receptors include the killer cell immunoglobulin-like receptors (KIRs) in humans, the lectin-like Ly49 dimers in the mouse and the lectin-like CD94-NKG2A heterodimers in both species (Yokoyama and Plougastel, 2003; Parham, 2005). A conserved feature of these inhibitory receptors resides in the presence of one or two intracytoplasmic inhibitory signaling domains called immunoreceptor tyrosinebased inhibition motifs (ITIMs; Burshtyn et al., 1996; Olcese et al., 1996). By interacting with MHC class I molecules that are constitutively expressed by most healthy cells in steady-state conditions but that may be lost upon stress, inhibitory MHC class I receptors provide a way for NK cells to ensure tolerance to self while allowing toxicity toward stressed cells. MHC class I is not the only constitutive self-signal detected by NK cells, as other inhibitory receptors (for example, mouse NKR-P1B, human NKR-P1A, and mouse 2B4) that recognize non-MHC selfmolecules (for example, Clr-b, LLT-1, and CD48, respectively) also regulate NK cell activation (Kumar and McNerney, 2005).

MHC class I-specific inhibitory receptors and their ligands (H-2 in mice and HLA in humans) are highly polymorphic molecules encoded by multigenic, multiallelic families of genes that are inherited independently (Yokoyama and Plougastel, 2003; Parham, 2005). NK cells have thus to discriminate self in a context where self-molecules differ from individuals to individuals. Like $\mathrm{T}$ lymphocytes, NK cells are educated to self versus altered-self discrimination. This education, also termed "tuning, licensing, or arming" leads to the maturation of a NK cell functional repertoire (i.e., the ensemble of stimulations toward which NK cells are reactive), which is adapted to selfMHC class I environment (Fernandez et al., 2005; Kim et al., 2005; Anfossi et al., 2006; Raulet and Vance, 2006; Yokoyama and Kim, 2006). Consequently, NK cells in MHC class I-deficient hosts are hyporesponsive to stimulatory receptor stimulation and thereby tolerant to self. Other studies have reported that the hyporesponsiveness of NK cells grown in a MHC class I-deficient environment can be overcome by inflammatory conditions in NK cell environment (Tay et al., 1995; Orr et al., 2010). It remains that two types of self-tolerant NK cells coexist in vivo at steady-state: functionally competent NK cells, whose effector responses are inhibited by the recognition of self-MHC class I molecules, and hyporesponsive NK cells that cannot detect self-MHC class I.NK cell education does not result in an on/off switch, but rather in a quantitative tuning of NK cell responsiveness: the more inhibitory receptors recognizing self-MHC class I are expressed, the more NK cells are responsive to cells lacking self-MHC class I (Brodin et al., 2009; Joncker et al., 2009; Hoglund and Brodin, 2010). The molecular mechanisms underlying the MHC-dependent NK cell education have been shown in mice to require a functional ITIM in the intracytoplasmic tail of Ly49 inhibitory receptors (Kim et al., 2005). Recently using spot variable fluorescence correlation spectroscopy to monitor the movement of receptors, we have shown that in NK cells genetically engineered to not be properly educated, 
inhibitory and activating receptors were confined together in domains where they were associated with an actin network at the plasma membrane (Guia et al., 2011). When these cells were educated by MHC class I recognition, inhibitory receptors remained associated with an actin meshwork at the membrane, while activating receptors were present in nanodomains characteristic of active receptor signaling (Guia et al., 2011). This mechanism, as compared to transcriptional reprogramming, may allow the NK cells greater flexibility to switch between an unresponsive state and a state in which they are competent to respond to stimuli, consistent with recent NK cell adoptive transfer experiments (Elliott et al., 2010; Joncker et al., 2010).

\section{STRESS-INDUCED SELF RECOGNITION}

Besides the detection of self via inhibitory receptors, NK cells are also equipped with cell surface activating receptors. In addition to the recognition of microbial molecules by a variety of innate immune receptors, the so-called "infectious non-self recognition," it has been shown that some receptors of innate immune cells can detect internal changes, leading to the concept of "stressinduced self recognition” (Bauer et al., 1999; Gasser et al., 2005; Guerra et al., 2008; Raulet and Guerra, 2009). This mode of detection is based on the recognition of molecules whose expression is barely detectable in steady-state conditions, but induced upon various forms of stress. A prototypical example of this mode of detection is illustrated by the activation of NK cells via engagement of the NKG2D receptor, which interacts with self-molecules selectively up-regulated on stressed cells, such as tumor cells. In vivo, NKG2D is critical for immunosurveillance of epithelial and lymphoid malignancies in transgenic models of de novo tumorigenesis (Guerra et al., 2008). In the transgenic $\mathrm{E} \mu$-Myc mouse model of spontaneous B cell lymphoma, the tumor expression of NKG2D ligands was shown to represent an early step of tumorigenesis associated with still unknown genetic lesions of cancer cells (Unni et al., 2008). A linkage between tumorigenesis, DNA damage response (DDR) and the immune response has been proposed: DNA-damaging agents or DNA lesions associated with tumorigenesis activate the DDR, which results in up-regulation of NKG2D ligands leading NK cells (and other NKG2D+ lymphocytes) to attack the diseased cells (Gasser et al., 2005; Gasser and Raulet, 2006).

Besides NKG2D, NK cell express an array of cell surface molecules, such as the natural cytotoxicity receptors (NCR), which have been shown since more than a decade to be involved in the activation of NK cells by tumor cells (Moretta et al., 2001). The NCR family includes NKp46 (NCR1, CD335), NKp44 (NCR2, CD336), and NKp30 (NCR3, CD337; Bottino et al., 2006). However, the NCR ligands that are expressed on tumor cells and activate NK cells are still unknown at the noticeable exception of B7-H6 that we recently identified as a ligand for NKp30 (Brandt et al., 2009). One important aspect of future research in NK cells, will be to characterize the nature and the regulation of NCR ligands.

\section{NK CELLS AND IMMUNOLOGICAL MEMORY}

The immune system, like the nervous system, has this ability to learn from previous experience, such as a single encounter with the many pathogens that exist. The result is immunological memory that confers longlasting protection. Until now, immunological memory was thought to be a feature of the adaptive immune system. Unexpectedly, recent studies revealed that NK cells could be players in the persistence of immunity, although they have traditionally been considered to be part of the innate immune system. First, a seminal study showed that in mice lacking $\mathrm{T}$ and $\mathrm{B}$ cells, a subset of liver NK cells are able to mediate the prototypical "adaptive" immune reaction of hapten-specific contact hypersensitivity (O'Leary et al., 2006; Paust et al., 2010). More recently, in a model of murine cytomegalovirus (MCMV), mouse NK cells expressing the receptor $\mathrm{Ly} 49 \mathrm{H}$, which recognizes the MCMV m157 protein, was shown to clonally expand and subsequently contract while leaving a few long-lived cells able to mount a "secondary" response (Sun et al., 2009; Ugolini and Vivier, 2009). These "virus-experienced" cells are still detectable up to 3 months after infection and display enhanced IFN- $\gamma$ secretion and degranulation compared to naïve cells when restimulated ex vivo. Finally, when transferred to naïve immunocompromised mice, these cells are more protective against a lethal virus chal- lenge. Following MCMV infection, NK cells can therefore give rise to a population of long-lived cells with an intrinsic ability to exhibit enhanced effector functions when restimulated. Supporting these observations, NK cells activated in vitro by cytokines (IL12/IL-18) and adoptively transferred in vivo also display some "memory-like" properties (Cooper et al., 2009). In this model, after an episode of "activation-driven" proliferation, a population of apparently resting cells with an enhanced ability to secrete IFN- $\gamma$ ex vivo is maintained during at least 3 weeks. Notably, this increased ability to secrete IFN- $\gamma$ was observed regardless of the cell generation. Thus, NK cells can retain in vivo an intrinsic memory of a prior in vitro activation, which is maintained across cell divisions. Altogether, these results prompt to research into the mechanisms that allow the boosted effector function of NK cells to be maintained across cell divisions, in particular the epigenetic marks associated with various stages of these cells' activation.

Besides, the "memory-like" features of NK cells also prompt to investigate how they participate in immunological memory. The ultimate goal of a vaccine is to develop long-lived immunological protection, whereby the first encounter with a pathogen is remembered and leads to an enhanced immune response. Novel insights into the cellular and molecular mechanisms controlling the development and function of the immunological memory are therefore critical for vaccine development and improvement. There are several reports showing that NK cells interfere with the shaping of the adaptive immune response (Raulet, 2004), but very few address specifically the role of NK cells in immunological memory (Raulet, 2004; Soderquest et al., 2011). Concerning primary responses, NK cells can meet dendritic cells (DC) in peripheral tissues, as well as in secondary lymphoid organs, and can act on them in two distinct ways (Moretta, 2002; Degli-Esposti and Smyth, 2005; Walzer et al., 2005). Upon interaction, NK cells can kill immature DC in humans and mice, thereby influencing DC homeostasis, but also potentially limiting DC-based vaccination efficacy. Conversely, the killing of target cells by NK cells can lead to the cross-presentation of antigens from apoptotic NK cell targets by subsets of DCs. This NK cell-mediated cytotoxicity 
of target cells induces robust antigen-specific adaptive immune responses involving $\mathrm{CD}^{+} \mathrm{T}$ cells, $\mathrm{CD} 4^{+} \mathrm{T}$ cells and antibodies (Krebs et al., 2009). Recognition and killing of target cells by NK cells might thus provide a new and powerful strategy for vaccine development. NK cells can also influence adaptive immune responses by directly acting on $\mathrm{T}$ and $\mathrm{B}$ cells. In the inflamed lymph node, NK cells can promote the priming of $\mathrm{CD}^{+} \mathrm{T}$ helper type 1 cells by secreting IFN- $\gamma$. NK cells can also kill activated $\mathrm{T}$ cells, unless the $\mathrm{T}$ cells express sufficient amounts of classical or non-classical MHC class I molecules. As a consequence, blockade of CD94NKG2A inhibitory receptors leads to NK cell cytotoxicity against activated $\mathrm{CD} 4^{+} \mathrm{T}$ cells, suggesting the use of blocking antibodies to NKG2A to prevent $\mathrm{CD} 4^{+} \mathrm{T}$ celldependent autoimmunity (Lu et al., 2007). As the nature of reliable biological markers of protective immunity is still a matter of debate, it is also exciting to consider that NK cells might be monitored as a potential protection correlate for testing the efficiency of vaccines under development.

\section{NK CELL-BASED THERAPIES}

Several studies suggest that the manipulation of NK cell missing-self recognition may have important clinical benefit in leukemic patients (Cooley et al., 2007; Ljunggren and Malmberg, 2007; Terme et al., 2008; Zitvogel et al., 2008). In particular, retrospective studies of KIR/HLA mismatched stem cell transplantation in acute myeloid leukemia patients showed that the lack of KIR engagement on donor NK cells by patient MHC class I molecules was associated with a significant reduced risk for leukemia relapse (Ruggeri et al., 2002). The manipulation of NK cell alloreactivity in these settings implies haploidentical hematopoietic transplantations, which are associated with considerable adverse effects, including graft versus host disease mediated by allogenic $\mathrm{T}$ cells. A safer strategy is to block NK cell inhibitory receptors in an autologous setting, and is currently tested in phase II clinical trials with a fully human anti-KIR monoclonal antibody (1-7F9; Romagne et al., 2009; Sola et al., 2009). This monoclonal antibody recognizes KIR2D inhibitor receptors and blocks their interaction with the human MHC class I molecules HLA-C, leading to NK cell-mediated lysis of leukemic cells. However, one of the main concerns for using this therapeutic approach in humans is the risk of generating a strong reactivity against normal self-tissues and/or to interfere with $\mathrm{NK}$ cell education. Therefore the precise understanding of NK cell education mechanisms is not only critical to describe this process as a model of education to self reactivity for cells of the innate immune system, but it is also pivotal for the development of innovative therapeutic strategies based on the manipulation of NK cell immunity.

\section{CONCLUSIONS}

Studies on NK cells, which integrate their function as a result of their education and their mode of recognition of target cells, have already provided a novel conceptual framework for the study of innate immunity that can serve as an inspiration for the study of other hematopoietic cells. The experimental evidence of the role of NK cells as innate components of the host defense against some viruses and tumors, and the potential efficacy in manipulating KIR/HLA class I recognition in anti-tumoral hematopoietic stem cell transplantation has initiated the research on NK cell-directed therapies. These protocols are likely to be used in combinatorial regimen with classical anti-cancer approaches. However, more knowledge is required before therapeutic breakthroughs can be envisioned in this direction. The absolute requirement for a better understanding of NK cell biology is also highlighted by the possibility of using NK cell-based therapies in other clinical indications such as autoimmunity, infectious diseases, immune deficiencies, and pathological pregnancy. In addition, the need for novel immuno-monitoring studies has emerged with the burst of tumor vaccines and the search for surrogate markers of efficacy of druggable components. However, given the complexity of NK cell biology, their standard monitoring (e.g., in vitro lysis of K562 leukemia cells) should be revisited, implemented, and internationally standardized. Furthermore, the detection of NK cell ligands of tumor cells could also be evaluated as possible prognostic markers.

Thus, almost 40 years after their discovery and despite the growing interest in both basic and clinical aspects of NK cell biology, several key elements of NK cell function and mode of action remain to be unveiled. Frontiers in NK cell biology provides a platform to highlight new knowledge on key aspects of NK cell biology from the nanoscopic to the organismal scales. In addition, Frontiers in NK cell biology has the ambition to also apply to human immunology by bridging basic and translational research to open novel therapeutic perspectives.

\section{ACKNOWLEDGMENTS}

Eric Vivier and Sophie Ugolini are supported by grants from the European Research Council (Advanced Grants), Agence Nationale de la Recherche (ANR), Ligue Nationale contre le Cancer (Equipe labellisée "La Ligue"), and institutional grants from INSERM, CNRS, and Université de la Méditerranée to the CIML. Eric Vivier is a scholar from the Institut Universitaire de France.

\section{REFERENCES}

Anfossi, N., Andre, P., Guia, S., Falk, C. S., Roetynck, S., Stewart, C. A., Breso, V., Frassati, C., Reviron, D., Middleton, D., Romagné, F., Ugolini, S., and Vivier, E. (2006). Human NK cell education by inhibitory receptors for MHC class I. Immunity 25, 331-342. Bauer, S., Groh, V., Wu, J., Steinle, A., Phillips, J. H., Lanier, L. L., and Spies, T. (1999). Activation of NK cells and T cells by NKG2D, a receptor for stress-inducible MICA. Science 285, 727-729.

Bix, M., Liao, N.-S., Zijlstra, M., Loring, J., Jaenisch, R., and Raulet, D. (1991). Rejection of class I MHCdeficient haemopoietic cells by irradiated MHCmatched mice. Nature 349, 329-331.

Bottino, C., Moretta, L., and Moretta, A. (2006). NK cell activating receptors and tumor recognition in humans. Curr. Top. Microbiol. Immunol. 298, 175-182.

Brandt, C. S., Baratin, M., Yi, E. C., Kennedy, J., Gao, Z., Fox, B., Haldeman, B., Ostrander, C. D., Kaifu, T., Chabannon, C., Moretta, A., West, R., Xu, W., Vivier, E., and Levin, S. D. (2009). The B7 family member B7-H6 is a tumor cell ligand for the activating natural killer cell receptor NKp30 in humans. J. Exp. Med. 206, 1495-1503.

Brodin, P., Karre, K., and Hoglund, P. (2009). NK cell education: not an on-off switch but a tunable rheostat. Trends Immunol. 30, 143-149.

Burshtyn, D. N., Scharenberg, A. M., Wagtmann, N., Rajagopalan, S., Berrada, K., Yi, T., Kinet, J.-P., and Long, E. O. (1996). Recruitment of tyrosine phosphatase HCP by the killer cell inhibitory receptor. Immunity 4, 77-85.

Cooley, S., June, C. H., Schoenberger, S. P., and Miller, J. S. (2007). Adoptive therapy with T cells/NK cells. Biol. Blood Marrow Transplant. 13(Suppl.) 1, 33-42.

Cooper, M. A., Elliott, J. M., Keyel, P. A., Yang, L., Carrero, J.A., and Yokoyama, W.M. (2009). Cytokine-induced memory-like natural killer cells. Proc. Natl. Acad. Sci. U.S.A. 106, 1915-1919.

Degli-Esposti, M. A., and Smyth, M. J. (2005). Close encounters of different kinds: dendritic cells and 
NK cells take centre stage. Nat. Rev. Immunol. 5, 112-124.

Elliott, J. M., Wahle, J. A., and Yokoyama, W. M. (2010). MHC class I-deficient natural killer cells acquire a licensed phenotype after transfer into an MHC class I-sufficient environment. J. Exp. Med. 207, 2073-2079.

Fernandez, N. C., Treiner, E., Vance, R. E., Jamieson, A. M., Lemieux, S., and Raulet, D. H. (2005). A subset of natural killer cells achieves self-tolerance without expressing inhibitory receptors specific for self-MHC molecules. Blood 105, 4416-4423.

Gasser, S., Orsulic, S., Brown, E. J., and Raulet, D. H. (2005). The DNA damage pathway regulates innate immune system ligands of the NKG2D receptor. Nature 436, 1186-1190.

Gasser, S., and Raulet, D. H. (2006). Activation and selftolerance of natural killer cells. Immunol. Rev. 214, 130-142.

Guerra, N., Tan, Y. X., Joncker, N. T., Choy, A., Gallardo, F., Xiong, N., Knoblaugh, S., Cado, D., Greenberg, N. M., and Raulet, D. H. (2008). NKG2D-deficient mice are defective in tumor surveillance in models of spontaneous malignancy. Immunity 28, 571-580.

Guia, S., Jaeger, B. N., Piatek, S., Mailfert, S., Trombik, T., Fenis, A., Chevrier, N., Walzer, T., Kerdiles, Y. M., Marguet, D., Vivier, E., and Ugolini, S. (2011). Confinement of activating receptors at the plasma membrane controls natural killer cell tolerance. Sci. Signal. 4, ra21.

Herberman, R. B., Nunn, M. E., and Lavrin, D. H. (1975). Natural cytotoxic reactivity of mouse lymphoid cells against syngeneic acid allogeneic tumors. I. Distribution of reactivity and specificity. Int. J. Cancer 16, 216-229.

Hoglund, P., and Brodin, P. (2010). Current perspectives of natural killer cell education by MHC class I molecules. Nat. Rev. Immunol. 10, 724-734.

Joncker, N. T., Fernandez, N. C., Treiner, E., Vivier, E., and Raulet, D. H. (2009). NK cell responsiveness is tuned commensurate with the number of inhibitory receptors for self-MHC class I: the rheostat model. J. Immunol. 182, 4572-4580.

Joncker, N. T., Shifrin, N., Delebecque, F., and Raulet, D. H. (2010). Mature natural killer cells reset their responsiveness when exposed to an altered MHC environment. J. Exp. Med. 207, 2065-2072.

Kärre, K., Ljunggren, H. G., Piontek, G., and Kiessling, R. (1986). Selective rejection of H-2-deficient lymphoma variants suggests alternative immune defense strategy. Nature 319, 675-678.

Kiessling, R., Klein, E., and Wigzell, H. (1975). "Natural” killer cells in the mouse. I. Cytotoxic cells with specificity for mouse Moloney leukemia cells. Specificity and distribution according to genotype. Eur. J. Immunol. 5, 112-117.

Kim, S., Poursine-Laurent, J., Truscott, S. M., Lybarger, L., Song, Y. J., Yang, L., French, A. R., Sunwoo, J. B., Lemieux, S., Hansen, T. H., and Yokoyama, W. M. (2005). Licensing of natural killer cells by host major histocompatibility complex class I molecules. Nature 436, 709-713.

Krebs, P., Barnes, M. J., Lampe, K., Whitley, K., Bahjat, K. S., Beutler, B., Janssen, E., and Hoebe, K. (2009). NK cell-mediated killing of target cells triggers robust antigen-specific $\mathrm{T}$ cell-mediated and humoral responses. Blood 113, 6593-6602.
Kumar, V., and McNerney, M. E. (2005). A new self: MHC-class-I-independent natural-killer-cell selftolerance. Nat. Rev. Immunol. 5, 363-374.

Lanier, L. L. (2005). NK cell recognition. Annu. Rev. Immunol. 23, 225-274.

Ljunggren, H. G., and Malmberg, K. J. (2007). Prospects for the use of NK cells in immunotherapy of human cancer. Nat. Rev. Immunol. 7, 329-339.

Lu, L., Ikizawa, K., Hu, D., Werneck, M. B., Wucherpfennig, K. W., and Cantor, H. (2007). Regulation of activated $\mathrm{CD} 4+\mathrm{T}$ cells by NK cells via the Qa-1-NKG2A inhibitory pathway. Immunity 26, 593-604.

Moretta, A. (2002). Natural killer cells and dendritic cells: rendezvous in abused tissues. Nat. Rev. Immunol. 2, 957-964.

Moretta, A., Bottino, C., Vitale, M., Pende, D., Cantoni, C., Mingari, M. C., Biassoni, R., and Moretta, L. (2001). Activating receptors and coreceptors involved in human natural killer cell-mediated cytolysis. Anпu. Rev. Immunol. 19, 197-223.

Moretta, L., and Moretta, A. (2004). Unravelling natural killer cell function: triggering and inhibitory human NK receptors. EMBO J. 23, 255-259.

Olcese, L., Lang, P., Vély, F., Cambiaggi, A., Marguet, D., Blery, M., Hippen, K. L., Biassoni, R., Moretta, A., Moretta, L., Cambier, J. C., and Vivier, E. (1996). Human and mouse killer-cell inhibitory receptors recruit PTP1C and PTP1D protein tyrosine phosphatases. J. Immunol. 156, 4531-4534.

Oldham, R. K., and Herberman, R. B. (1973). Evaluation of cell-mediated cytotoxic reactivity against tumor associated antigens with 125I-iododeoxyuridine labeled target cells. J. Immunol. 111, 862-871.

O'Leary J, G., Goodarzi, M., Drayton, D. L., and von Andrian, U.H. (2006). T cell- and B cell-independent adaptive immunity mediated by natural killer cells. Nat. Immunol. 7, 507-516.

Orr, M. T., Murphy, W. J., and Lanier, L. L. (2010). 'Unlicensed' natural killer cells dominate the response to cytomegalovirus infection. Nat. Immunol. 11, 321-327.

Parham, P. (2005). MHC class I molecules and KIRs in human history, health and survival. Nat. Rev. Immunol. 5, 201-214.

Paust, S., Gill, H. S., Wang, B.Z., Flynn, M. P., Moseman, E. A., Senman, B., Szczepanik, M., Telenti, A., Askenase, P.W., Compans, R.W., and von Andrian, U. H. (2010). Critical role for the chemokine receptor CXCR6 in NK cell-mediated antigen-specific memory of haptens and viruses. Nat. Immunol. 11, 1127-1135.

Raulet, D. H. (2004). Interplay of natural killer cells and their receptors with the adaptive immune response. Nat. Immunol. 5, 996-1002.

Raulet, D. H., and Guerra, N. (2009). Oncogenic stress sensed by the immune system: role of natural killer cell receptors. Nat. Rev. Immunol. 9, 568-580.

Raulet, D. H., and Vance, R. E. (2006). Self-tolerance of natural killer cells. Nat. Rev. Immunol. 6, 520-531.

Romagne, F., Andre, P., Spee, P., Zahn, S., Anfossi, N., Gauthier, L., Capanni, M., Ruggeri, L., Benson, D. M. Jr., Blaser, B. W., Della Chiesa, M., Moretta, A., Vivier, E., Caligiuri, M. A., Velardi, A., and Wagtmann, N. (2009). Preclinical characterization of 1-7F9, a novel human anti-KIR therapeutic antibody that augments natural killer-mediated killing of tumor cells. Blood 114, 2667-2677.

Ruggeri, L., Capanni, M., Urbani, E., Perruccio, K., Shlomchik, W. D., Tosti, A., Posati, S., Rogaia, D.,
Frassoni, F., Aversa, F., Martelli, M. F., and Velardi, A. (2002). Effectiveness of donor natural killer cell alloreactivity in mismatched hematopoietic transplants. Science 295, 2097-2100.

Soderquest, K., Walzer, T., Zafirova, B., Klavinskis, L. S., Polic, B., Vivier, E., Lord, G. M., and Martin-Fontecha, A. (2011). Cutting edge: $\mathrm{CD} 8+\mathrm{T}$ cell priming in the absence of NK cells leads to enhanced memory responses. J. Immunol. 186, 3304-3308.

Sola, C., Andre, P., Lemmers, C., Fuseri, N., Bonnafous, C., Blery, M., Wagtmann, N. R., Romagne, F., Vivier, E., and Ugolini, S. (2009). Genetic and antibody-mediated reprogramming of natural killer cell missing-self recognition in vivo. Proc. Natl. Acad. Sci. U.S.A. 106, 12879-12884.

Sun, J. C., Beilke, J. N., and Lanier, L. L. (2009). Adaptive immune features of natural killer cells. Nature 457, 557-561.

Tay, C. H., Welsh, R. M., and Brutkiewicz, R. R. (1995). NK cell response to viral infections in beta 2-microglobulin-deficient mice. J. Immunol. 154, 780-789.

Terme, M., Ullrich, E., Delahaye, N. F., Chaput, N., and Zitvogel, L. (2008). Natural killer cell-directed therapies: moving from unexpected results to successful strategies. Nat. Immunol. 9, 486-494.

Ugolini, S., and Vivier, E. (2009). Immunology: natural killer cells remember. Nature 457, 544-545.

Unni, A. M., Bondar, T., and Medzhitov, R. (2008). Intrinsic sensor of oncogenic transformation induces a signal for innate immunosurveillance. Proc. Natl. Acad. Sci. U.S.A. 105, 1686-1691.

Vivier, E., Nunes, J. A., and Vely, F. (2004). Natural killer cell signaling pathways. Science 306, 1517-1519.

Vivier, E., Raulet, D. H., Moretta, A., Caligiuri, M. A., Zitvogel, L., Lanier, L. L., Yokoyama, W. M., and Ugolini, S. (2011). Innate or adaptive immunity? The example of natural killer cells. Science 331, 44-49.

Vivier, E., Tomasello, E., Baratin, M., Walzer, T., and Ugolini, S. (2008). Functions of natural killer cells. Nat. Immunol. 9, 503-510.

Walzer, T., Dalod, M., Robbins, S. H., Zitvogel, L., and Vivier, E. (2005). Natural-killer cells and dendritic cells: "l'union fait la force". Blood 106, 2252-2258.

Yokoyama, W. M., and Kim, S. (2006). How do natural killer cells find self to achieve tolerance? Immunity 24, 249-257.

Yokoyama, W. M., and Plougastel, B. F. (2003). Immune functions encoded by the natural killer gene complex. Nat. Rev. Immunol. 3, 304-316.

Zitvogel, L., Apetoh, L., Ghiringhelli, F., and Kroemer, G. (2008). Immunological aspects of cancer chemotherapy. Nat. Rev. Immunol. 8, 59-73.

Received: 17 May 2011; accepted: 20 May 2011; published online: 03 June 2011.

Citation: Vivier E and Ugolini S (2011). Natural killer cells: from basic research to treatments. Front. Immun. 2:18. doi: 10.3389/fimmu. 2011.00018

This article was submitted to Frontiers in NK Cell Biology, a specialty of Frontiers in Immunology.

Copyright $\odot 2011$ Vivier and Ugolini. This is an open-access article subject to a non-exclusive license between the authors and Frontiers Media SA, which permits use, distribution and reproduction in other forums, provided the original authors and source are credited and other Frontiers conditions are complied with. 